\title{
Three-Dimensional Right Ventriculo-Arterial Coupling as an Independent Correlate of Severe Heart Failure Symptoms in Patients with Dilated Cardiomyopathy
}

\author{
Aura Vijiiac ${ }^{1}$, Sebastian Onciul ${ }^{1}$, Silvia Deaconu ${ }^{2}$, Radu Vatasescu ${ }^{3}$, Claudia Guzu ${ }^{4}$, \\ Violeta Verinceanu ${ }^{5}$, Alina Scarlatescu ${ }^{4}$, Diana Zamfir ${ }^{4}$, Ioana Petre ${ }^{1}$, Alexandru Scafa \\ Udriste $^{1}$, and Maria Dorobantu ${ }^{1}$ \\ ${ }^{1}$ Carol Davila University of Medicine and Pharmacy \\ ${ }^{2}$ Emergency Clinical Hospital of Bucharest \\ ${ }^{3}$ Clinical Emergency Hospital Bucharest \\ ${ }^{4}$ Emergency Clinical Hospital, Bucharest \\ ${ }^{5}$ Emergency Clinical Hospital Bucharest
}

September 25, 2021

\begin{abstract}
Background: Right ventricular-pulmonary artery coupling (RVPAC) is a predictor of outcome in pulmonary hypertension. However, the role of this parameter in dilated cardiomyopathy (DCM) remains to be established. The aim of this study was to assess the contribution of RVPAC to the occurrence of severe heart failure (HF) symptoms in patients with DCM using three-dimensional (3D) echocardiography. Methods: We prospectively screened 139 outpatients with DCM, 105 of whom were enrolled and underwent 3D echocardiographic assessment. RVPAC was estimated non-invasively as the 3D right ventricular stroke volume (SV) to end-systolic volume (ESV) ratio. Severe HF symptoms were defined by New York Heart Association (NYHA) class III or IV. We evaluated differences in RVPAC across NYHA classes and the ability of RVPAC to predict severe symptoms. Results: Mean left ventricular (LV) ejection fraction was $28 \pm 7 \%$. Mean RVPAC was $0.77 \pm 0.30$ and it was significantly more impaired with increasing symptom severity $(\mathrm{p}=0.001)$. RVPAC was the only independent correlate of severe HF symptoms, after adjusting for age, diuretic use, LV systolic function, LV diastolic function and pulmonary artery systolic pressure (OR 0.035 [95\% CI, $0.004-0.312], \mathrm{p}=0.003$ ). By receiver-operating characteristic analysis, the RVPAC cut-off value for predicting severely symptomatic status was 0.54 (area under the curve $=0.712, \mathrm{p}<0.001$ ). Conclusion: $3 \mathrm{D}$ echocardiographic $\mathrm{SV} / \mathrm{ESV}$ ratio is an independent correlate of severe HF symptoms in patients with DCM. 3D RVPAC might prove to be a useful risk stratification tool for these patients, should it be further validated in larger studies.
\end{abstract}

\section{INTRODUCTION}

Right ventricular (RV) dysfunction was established to be an important outcome predictor in both arterial pulmonary hypertension (PH) [1] and left heart disease [2]. Beyond RV systolic performance, the mechanical efficiency of the ventriculo-vascular interplay also has prognostic implications [3-4]. The right ventricularpulmonary artery coupling (RVPAC) reflects the interaction between the right heart and the pulmonary circulation unit, which is optimal when all the mechanical energy of the RV is transferred to the vascular bed [5], providing an adequate cardiac output with minimal energy consumption [6].

RVPAC is defined as the ratio between end-systolic RV elastance (EES) and pulmonary arterial elastance (Ea), which is calculated using pressure-volume loops derived from right heart catheterization (RHC). Due to its technical complexity, the assessment of RVPAC is not routinely performed. However, non-invasive 
estimation of RVPAC can be done using cardiac magnetic resonance (CMR) [7] or transthoracic echocardiography [8], and non-invasive parameters showed good correlation with catheterisation-derived measurements [7-10]. Three-dimensional (3D) echocardiography overcomes the pitfalls of conventional RV functional assessment [11] and has been validated against CMR [12]. A 3D echocardiographic estimation of RVPAC has been proposed, as the ratio between RV stroke volume (SV) and RV end-systolic volume (ESV), which was found to have good correlation with catheterisation-derived RVPAC [13].

We hypothesized that right ventriculo-vascular decoupling plays a role in the occurrence of heart failure (HF) symptoms in patients with dilated cardiomyopathy (DCM). Consequently, our aim was to evaluate the RVPAC using 3D echocardiography in patients with DCM and to assess its relationship with the severity of HF symptoms in this setting.

\section{METHODS}

\section{Study population}

We prospectively screened 139 consecutive outpatients with non-ischaemic DCM who were referred to our echocardiography department. DCM was defined using the following criteria: (1) end-diastolic left ventricular $(\mathrm{LV})$ volume index $>74 \mathrm{ml} / \mathrm{m}^{2}$ in males and $>61 \mathrm{ml} / \mathrm{m}^{2}$ in females, according to cut-offs from the current guidelines of chamber quantification [14] and (2) LV ejection fraction (EF) $<40 \%$ by two-dimensional (2D) Simpson biplane method. We excluded patients with atrial fibrillation (15 patients), poor acoustic window or inability to hold breath (10 patients), conduction disturbances (3 patients) and cor pulmonale (6 patients), leaving a final study population of 105 patients. Included patients were clinically stable (i.e., with no change in diuretic dose for at least 2 weeks prior to enrollment).

Three investigators collected basic demographic and clinical data. Patients' clinical status was assessed by a physician using the New York Heart Association (NYHA) classification. Severe symptoms of HF were defined by NYHA class III or IV. BNP serum levels were available in 62 patients. Informed consent was obtained from all patients and the study protocol was approved by the local human research committee.

\section{Two-dimensional echocardiographic assessment}

All patients underwent comprehensive two-dimensional (2D) echocardiographic examinations, performed with a Vivid E9 (GE Vingmed, Horten, Norway) ultrasound machine equipped with a M5S probe, according to current recommendations [15]. Three experienced researchers performed offline data analysis using dedicated software (EchoPAC BT 12).

LV dimensions, systolic and diastolic function were assessed according to international recommendations [14-16]. LV volumes and LV ejection fraction (EF) were measured using the biplane Simpson method from the apical four- and two-chamber views. Using pulsed-wave tissue Doppler imaging (TDI) at the septal and lateral site of the mitral annulus, we calculated myocardial velocities and we estimated LV filling pressures from the ratio of early diastolic transmitral velocity (E) to average e' wave. For LV global longitudinal strain (GLS), we used high frame rate acquisitions (50-70 frames per second) and a 17-segment model by speckle tracking echocardiography (STE), as previously described [17].

Conventional parameters of RV function such as tricuspid annular plane systolic excursion (TAPSE), peak systolic TDI velocity of the tricuspid annulus ( $\mathrm{S}$ wave) and RV fractional area change (RV-FAC) were measured from apical RV-focused view, according to current guidelines [15, 18]. For RV strain analysis we used software designed for the LV (EchoPAC - Q Analysis package) and we manually traced the endocardial border of the RV from the apical RV-focused view, as recommended $[19,20]$. The RV free wall (RVFW) and the interventricular septum were each divided into three segments. The global longitudinal strain of the RV (GLS-RV) represents the average of all six segmental strain values. The longitudinal strain of the RVFW (RVFW-LS) is the average of the segmental values of the RVFW. Estimation of pulmonary artery systolic pressure (PASP) was made using the gradient between the RV and the right atrium (RA) - obtained from the continuous-wave Doppler spectrum of the tricuspid regurgitation (TR) jet - and the estimated RA pressure, based on the inferior vena cava (IVC) diameter and respiratory changes [15]. TR severity was graded based 
on qualitative Doppler criteria, such as color flow jet area and the shape and density of the TR jet envelope $[21]$.

\section{Three-dimensional echocardiographic assessment}

Six-beat full-volume 3D acquisitions, with electrocardiographic gating during breath holding, were performed after the 2D examination by the same researcher using the $4 \mathrm{~V}$ probe. LV-focused 3D data sets were obtained from the apical four-chamber view, while RV-focused 3D data sets were obtained from the apical RV-focused view, as recommended [12]. Image post-processing and reconstruction were performed offline using 4D AutoLVQ software (EchoPAC BT 12, GE Vingmed-Ultrasound, Horten, Norway) for the LV volumes and LVEF and 4D RV-Function software (TomTec Imaging Systems, Unterschleissheim, Germany) for the RV volumes and RVEF (Figure 1). The endocardial surface of the ventricles was traced at both end-systole and enddiastole $[14,15]$. Subsequently, the software generated the biventricular volumes and ejection fractions.

We estimated the RVPAC non-invasively as the ratio between the 3D RV SV and the 3D RV ESV. This ratio has been previously used as a marker of the ventriculo-vascular interaction $[7,22,23]$ and it has shown good correlation with invasive RVPAC derived from RHC [13].

\section{Statistical analysis}

Variables were checked for the normality of distribution using Kolmogorov-Smirnov test. Continuous data were presented as mean \pm standard deviation if normally distributed, while skewed data were presented as median and corresponding interquartile range. In order to compare variables between different NYHA classes, we used one-way ANOVA or Kruskal-Wallis test, as dictated by distribution, with a Bonferroni posthoc correction. We used Pearson's correlation coefficient to assess correlations between continuous variables. Categorical data were expressed as numbers and percentages and they were compared using either $\chi^{2}$ test or Fisher exact test, as appropriate.

Correlates of severe HF symptoms were assessed using binary logistic regression. Receiver operating characteristic (ROC) curves and the respective area under the curve (AUC) were used to assess the accuracy of each parameter to identify severe symptoms of HF. A cut-off value for each parameter was chosen based on the highest sum of sensitivity and specificity. Variables with statistical significance in univariable analysis were included in the multivariable model, which also included age - regardless of its significance in univariable analysis. Results were reported as odds ratios (OR) with $95 \%$ confidence intervals (CI). All statistical analysis was performed using SPSS version 20.0 statistical software package and P-values $<0.05$ were considered statistically significant.

Intra- and interobserver reproducibility of RVPAC was evaluated in 10 randomly selected patients, using intraclass coefficient (ICC) on a two-way mixed-effects model. We found a good intra- and interobserver reproducibility ( $\mathrm{ICC}=0.90$ [95\% CI, 0.61-0.98] and ICC $=0.84$ [95\% CI, 0.41-0.96], respectively).

\section{RESULTS}

\section{Study population}

Baseline demographic and clinical characteristics of the study group are summarised in Table 1. Of the 105 patients enrolled, $11(10.5 \%)$ were asymptomatic (NYHA class I) and $54(51.4 \%)$ were in NYHA class II. 40 (38.1\%) patients from our cohort had severe symptoms of HF: there were 31 (29.5\%) patients in NYHA class III and $9(8.6 \%)$ patients in NYHA class IV. Mean age in the study group was $61 \pm 14$ years and the majority were men (73\%). Asymptomatic patients were significantly younger ( $51 \pm 10$ years) than both patients in NYHA class II (62 \pm 13 years) and severely symptomatic patients $(62 \pm 14$ years, $\mathrm{p}=0.048)$, and they had significantly less diuretic use $(27 \%$, versus $91 \%$ and $93 \%$, respectively, $\mathrm{p}=0.002)$. There were no significant differences in terms of age and comorbidities between patients in various NYHA classes (Table 1). BNP levels were significantly higher in patients with severe symptoms.

\section{Echocardiographic data}


The 2D echocardiographic characteristics are summarised in Table 2. Mean LVEF in the study group was $28 \pm 7 \%$. There were no significant differences in LVEF across different categories of HF symptoms $(\mathrm{p}=0.06)$. However, LV GLS was significantly more impaired in severely symptomatic patients $(-6.7 \% \pm 2.8 \%)$ than in asymptomatic $(-9.8 \% \pm 3.2 \%)$ and mildly symptomatic patients $(-8.3 \% \pm 2.6 \%, \mathrm{p}=0.002)$. Patients with severe symptoms also had higher E/A ratio and higher E/E' ratio, reflecting a more impaired LV diastolic function. There were no significant differences in PASP across different NYHA classes $(p=0.29)$.

Both TAPSE and $\mathrm{S}$ wave velocity were significantly lower in patients with severe HF symptoms $(\mathrm{p}=0.002$ for both). Mean GLS-RV in the study group was $-12 \pm 5 \%$, while mean RVFW-LS was $-15 \pm 7.9 \%$. Both GLSRV and RVFW-LS were significantly more impaired in severely symptomatic patients $(\mathrm{p}=0.01$ and $\mathrm{p}=0.03$, respectively) and they showed an excellent positive correlation with each other $(\mathrm{r}=0.87, \mathrm{p}=<0.001)$.

3D echocardiographic data are summarized in Table 3. 3D LVEF was positively correlated with 2D LVEF $(\mathrm{r}=0.90, \mathrm{p}<0.001)$ and negatively correlated to GLS-LV $(\mathrm{r}=-0.64, \mathrm{p}<0.001)$. Mean 3D RVEF in the study group was $42 \pm 9 \%$ and it was significantly lower in patients with severe HF symptoms. RVEF was negatively correlated with GLS-RV ( $\mathrm{r}=-0.51, \mathrm{p}<0.001)$ and RVFW-LS $(\mathrm{r}=-0.47, \mathrm{p}<0.001)$. The mean RVPAC was $0.77 \pm 0.30$ and it differed significantly across different NYHA classes, being lowest in patients with severe symptoms of HF (Figure 2). RVPAC was positively correlated with TAPSE $(\mathrm{r}=0.37, \mathrm{p}<0.001$ ), S wave velocity $(\mathrm{r}=0.28, \mathrm{p}=0.004)$, RV-FAC $(\mathrm{r}=0.25, \mathrm{p}=0.01)$, RVEF $(\mathrm{r}=0.97, \mathrm{p}<0.001)$ and negatively correlated with GLS-RV $(\mathrm{r}=-0.48, \mathrm{p}<0.001)$ and RVFW-LS $(\mathrm{r}=-0.43, \mathrm{p}<0.001)$. No correlation was found between RVPAC and either PASP $(\mathrm{p}=0.50)$, tricuspid E/A ratio $(\mathrm{p}=0.46)$ or tricuspid $\mathrm{E} / \mathrm{E}$ ' ratio $(\mathrm{p}=0.13)$.

\section{Correlates of severe heart failure symptoms in patients with DCM}

Parameters were tested in univariable analysis for their ability to predict severe symptoms. Variables were divided in five categories: clinical characteristics, LV systolic function, LV diastolic function, RV function and PASP. For clinical characteristics we tested parameters which differed significantly across different NYHA classes (Table 1). Since BNP serum levels were not available for all patients, this parameter was excluded from the logistic regression. For LV systolic and diastolic function, we tested well-established parameters such as LVEF, GLS-LV and, respectively, mitral E/E' ratio and LA volume index. For RV function we chose traditional parameters of RV systolic function which differed across NYHA classes (Table 2), together with 3D RVPAC. The main correlates of severe HF are shown in Table 4. To compare the accuracy of these parameters, we performed ROC analysis and calculated the corresponding AUC (Table 5). The best result was found for RVPAC $(\mathrm{AUC}=0.712, \mathrm{p}<0.001)$, with a cut-off value of 0.54 for identifying severely symptomatic patients (47.5\% sensitivity, $92.3 \%$ specificity). The parameter with the highest statistical significance and highest AUC from each of the five above-mentioned categories was introduced in the multivariable logistic regression, together with age (Table 6). RVPAC emerged as the only independent correlate of severe HF symptoms in our study population (odds ratio, 0.035 [95\% CI, $0.004-0.312], \mathrm{p}=0.003$ ).

\section{DISCUSSION}

The main findings of this study are the following: (1) non-invasive 3D RVPAC was correlated with parameters of RV systolic function; (2) RVPAC was significantly lower in patients with severe disease (3) RVPAC was the only independent correlate of severe HF symptoms in our patients with DCM.

While the RV dysfunction has emerged as a powerful predictor in left heart disease, it is well-known that RV assessment with echocardiography is challenging, with no perfect single parameter describing RV function [24]. 3D echocardiography overcomes most of the limitations and geometric assumptions of $2 \mathrm{D}$ echocardiography [11] and its use is growing in experienced centres.

The RV adapts to chronic increase in pulmonary vascular resistance by increasing its contractility, which is able to increase 4- to 5-fold [25]. This is done initially by hypertrophy and remodelling, as described by the Frank-Starling law of the heart. If the increase in afterload is uncontrolled and prolonged, in the attempt to maintain an adequate cardiac output, the RV will begin to dilate. This will lead to increased myocyte stress, with progressive decrease of EF, ventriculo-vascular mismatch and ultimately RV failure [25]. 
Although uncoupling occurs in late stages of pressure overload, it precedes clinically overt RV failure [26]. Consequently, studies aimed to find simplified methods to measure RVPAC, in order to detect patients at risk of developing RV dysfunction. Non-invasive RVPAC - usually estimated as the TAPSE/ PASP ratio proved to have a prognostic role in patients with $\mathrm{PH}$ [27], HF with preserved [10] or reduced EF [28], acutely decompensated HF [29] and secondary TR [30].

In our study, we estimated RVPAC as the 3D SV/ESV ratio, which was significantly more impaired in patients with severe HF symptoms. 3D RVPAC might thus be proposed as a marker of disease severity in DCM patients. The SV/ESV ratio was first validated as a reliable surrogate for RVPAC with CMR, showing good correlation with invasive measurements [7]. Aubert et al. used 3D echocardiography to assess RVPAC in patients with $\mathrm{PH}$, finding that $3 \mathrm{D} \mathrm{SV} / \mathrm{ESV}$ ratio has a good correlation with the reference measurements of ventricular/arterial elastance ratio derived from RHC [13]. A few studies found the SV/ESV ratio to be an independent predictor of adverse outcome in patients with PH $[22,23]$. However, this is the first study so far to assess the role of 3D RVPAC in patients with DCM.

The energy transfer from the RV to the arterial bed is maximal when invasive RVPAC is between 1.5 and 2, with significant uncoupling occurring when RVPAC is less than 1 [26]. In our cohort, the mean SV/ESV ratio was $0.77 \pm 0.30$ and the ratio was less than 1 in $79 \%$ of the patients. This apparently high prevalence of uncoupling has two explanations. On one side, it is known that RVPAC is significantly depressed before overt RV failure occurs [31]. On the other side, the volumetric method for RVPAC assessment uses the assumption that RV volume at zero filling pressure is equal to zero, which will lead to an underestimation of coupling $[23,32]$.

How RV functional parameters reflect the matching of RV contractility to increased pulmonary vascular resistance remains to be clarified. The RVPAC showed a good correlation with the RVEF in our cohort. However, a previous study that assessed both the SV/ESV ratio and the RVEF in PH found only the SV/ESV ratio to be an independent outcome predictor [23]. Since the ESV changes less than the enddiastolic volume at any given change in venous return, the SV/ESV ratio is less load-dependent than the EF and it is thus considered more sensitive to early changes in severe PH [33-35].

DCM is a heterogenous disease in terms of etiology, clinical presentation, regional ventricular function, and outcome. NYHA classification has been long used as a fundamental tool for risk stratification and candidacy for therapeutic strategies [36], since higher NYHA class is a well-known, powerful predictor of adverse outcome [37-38]. Identifying independent correlates of HF in DCM patients is thus of major importance.

We aimed to define the RVPAC value at which significant RV maladaptation begins in patients with DCM. In our study, RVPAC $<0.54$ accurately predicted severe HF symptoms, independent of age, diuretic use, LV systolic and diastolic function and PASP. It is not surprising that severe symptoms occurred at a significant level of uncoupling, since RVPAC has considerable reserve before the development of overt RV failure [31]. None of the LV functional parameters was an independent correlate of severe HF in our patients. This might be explained by the narrow range of impaired LVEF/GLS-LV and of elevated LV filling pressures in our cohort. PASP was not an independent correlate of severe symptoms either; moreover, it did not modify the prediction power of RVPAC in multivariable regression. In fact, symptom severity in our patients with DCM was not related to the degree of pulmonary hypertension, but to the degree of RV maladaptation to its afterload. This highlights the importance of evaluating the cardiopulmonary unit as a whole.

\section{Study limitations}

Our study had several limitations. First, it was a single-centre study, with a relatively small sample size. Further studies are needed to evaluate if our results apply to larger populations of DCM patients. Second, there are limitations inherent to 3D echocardiographic assessment, which is unreliable when a good acoustic window is lacking. The reproducibility of 3D RVPAC was good in our study, but we did have a risk of selection bias, since we excluded patients with poor acoustic window. Third, using the volume method for estimating RVPAC as the SV/ESV ratio will lead to underestimation of RVPAC. Nevertheless, the predictive value of the SV/ESV ratio in $\mathrm{PH}$ has been previously shown; in our study, this ratio was the only independent 
correlate of severely symptomatic status in a disease primarily involving the left heart.

\section{CONCLUSIONS}

This study found that 3D RVPAC is an independent correlate of severe HF symptoms in patients with DCM. This reinforces the idea that right ventriculo-vascular interaction is more than the sum of its parts and that it should be taken into consideration in patients with DCM.

\section{Acknowledgements}

This work was supported by CREDO Project - ID: 49182, financed by the National Authority of Scientific Research and Innovation, on behalf of the Romanian Ministry of European Funds- through the Sector Operational Program "Increasing of Economic Competitiveness", Priority Axis 2, Operation 2.2.1 (SOP IEC -A2-0.2.2.1-2013-1) co-financed by the European Regional Development Fund.

Author contribution : Conceptualization: AV; Methodology: SO; Data acquisition: AV, CG, VV, IP, AS, SD; Data analysis and interpretation: AV, DZ, AS-U, RV; Writing - original draft preparation: AV; Writing - review and editing: SO, RV, MD; Supervision: MD; Final approval of manuscript: all authors

\section{References}

1. Fine NM, Chen L, Bastiansen PM et al. Outcome Prediction by Quantitative Right Ventricular Function Assessment in 575 subjects Evaluated for Pulmonary Hypertension. Circ Cardiovasc Imaging2013;6:711-721. doi:10.1161/CIRCIMAGING.113.000640

2. Seo J, Jung IH, Park JH et al. The Prognostic Value of 2D Strain in Assessment of the Right Ventricle in Patients with Dilated Cardiomyopathy. Eur Heart J Cardiovasc Imaging2019;20(9):1043-1050. doi:10.1093/ehjci/jez015

3. Nakaya T, Ohira H, Sato T et al. Right ventriculo-pulmonary arterial uncoupling and poor outcomes in pulmonary arterial hypertension.Pulm Circ 2020;10(3):1-11. doi: 10.1177/2045894020957223

4. Ikonomidis I, Aboyans V, Blacher J et al. The role of ventricular-arterial coupling in cardiac disease and heart failure: assessment, clinical implications and therapeutic interventions. A consensus document of the European Society of Cardiology Working Group on Aorta \& Peripheral Vascular Diseases, European Association of Cardiovascular Imaging, and Heart Failure. Eur J Heart Fail2019;21:402-424

5. Vonk Noordegraaf A, Chin KM, Haddad F et al. Pathophysiology of the right ventricle and of the pulmonary circulation in pulmonary hypertension: an update. Eur Respir $J$ 2019;53:1801900

6. Guarracino F, Baldassarri R, Pinsky MR. Ventriculo-arterial decoupling in acutely altered hemodynamic states. Critical Care2013;17:213

7. Sanz J, Garcia-Alvarez A, Fernandez-Friera L et al. Right ventriculo-arterial coupling in pulmonary hypertension: a magnetic resonance study. Heart 2012;98:238-243

8. Schmeisser A, Rauwolf T, Groscheck T et al. Pressure-volume loop validation of TAPSE/PASP for right ventricular arterial coupling in heart failure with pulmonary hypertension. Eur Heart $J$ Cardiovasc Imaging 2021;22:168-176

9. Tello K, Wan J, Dalmer A et al. Validation of the tricuspid annular plane systolic excursion/systolic pulmonary artery pressure ratio for the assessment of right ventricular-arterial coupling in severe pulmonary hypertension. Circ Cardiovasc Imaging2019;12:e009047. DOI: 10.1161/ CIRCIMAGING.119.009047

10. Guazzi M, Dixon D, Labate V et al. RV contractile function and its coupling to pulmonary circulation in heart failure with preserved ejection fraction. Stratification of clinical phenotypes and outcomes. JACC Cardiovasc Imaging 2017;10:1211-21

11. Smolarek D, Gruchala M, Sobiczewski W. Echocardiographic Evaluation of Right Ventricular Systolic Function: The Traditional and Innovative Approach. Cardiol J 2017;24;5:563-572

12. Muraru D, Spadotto V, Cecchetto A et al. New Speckle-Tracking Algorithm for Right Ventricular Volume Analysis from Three-Dimensional Echocardiographic Data Sets: Validation with Cardiac Magnetic Resonance and Comparison with the Previous Analysis Tool. Eur Heart J Cardiovasc Imaging 2016;17:1279-1289. doi:10.1093/ehjci/jev309 
13. Aubert $\mathrm{R}$, Venner $\mathrm{C}$, Huttin $\mathrm{O}$ et al. Three-dimensional echocardiography for the assessment of right ventriculo-arterial coupling. $J$ Am Soc Echocardiogr 2018;31(8):905-915. doi:10.1016/j.echo.2018.04.013.Epub2018 Jun 27

14. Lang RM, Badano PL, Mor-Avi V et al. Recommendations for Cardiac Chamber Quantification by Echocardiography in Adults: An Update from the American Society of Echocardiography and the European Association of Cardiovascular Imaging. Eur Heart J Cardiovasc Imaging 2015;16:233-271

15. Mitchell C, Rahko PS, Blauwet LA et al. Guidelines for Performing a Comprehensive Transthoracic Echocardiographic Examination in Adults: Recommendations from the American Society of Ehocardiography. J Am Soc Echocardiogr 2019;32(1):1-64. doi:10.1016/j.echo.2018.06.004

16. Nagueh SF, Smiseth OA, Appleton CP et al. Recommendations for the Evaluation of Left Ventricular Diastolic Function by Echocardiography and the European Association of Cardiovascular Imaging. Eur Heart J Cardiovasc Imaging 2016;17:1321-60

17. Voigt JU, Pedrizzetti G, Lysyansky P et al. Definitions for a Common Standard for 2D Speckle Tracking Echocardiography: Consensus Document of the EACVI/ASE/Industry Task Force to Standardize Deformation Imaging $J$ Am Soc Echocardiogr 2015;28:183-193

18. Rudski LG, Lai WW, Afilalo J et al. Guidelines for the Echocardiographic Assessment of the Right Heart in Adults: A Report from the American Society of Echocardiography Endorsed by the European Association of Echocardiography, a Registered Branch of the European Society of Cardiology, and the Canadian Society of Echocardiography.J Am Soc Echocardiogr 2010; 23: 685-713

19. Muraru D, Onciul S, Peluso D et al. Sex- and Method-Specific Reference Values for Right Ventricular Strain by 2-Dimensional Speckle-Tracking Echocardiography. Circ Cardiovasc Imaging 2016 Feb;9(2):e003866. doi:10.1161/IRCIMAGING.115.003866

20. Badano LP, Kolias TJ, Muraru D et al. Standardization of Left Atrial, Right Ventricular, and Right Atrial Deformation Imaging Using Two-Dimensional Speckle-Tracking Echocardiography: A Consensus Document of the EACVI/ASE/Industry Task Force to Standardize Deformation Imaging. Eur Heart $J$ Cardiovasc Imaging2018;19:591-600

21. Zoghbi WA, Adams D, Bonow RO et al. Recommendations for Noninvasive Evaluation of Native Valvular Regurgitation: A Report from the American Society of Echocardiography Developed in Collaboration with the Society for Cardiovascular Magnetic Resonance. J Am Soc Echocardiogr 2017;30:303-71

22. Jone PN, Schafer M, Pan Z et al. Right Ventricular-Arterial Coupling Ratio Derived from 3-Dimensional Echocardiography Predicts Outcomes in Pediatric Pulmonary Hypertension. Circ Cardiovasc Imaging 2019;12:e008176 DOI:10.1161/ CIRCIMAGING.118.008176

23. Vanderpool RR, Pinsky MR, Naeije R et al. Right Ventricular-Pulmonary Arterial Coupling Predicts Outcome in Patients Referred for Pulmonary Hypertension. Heart 2015;101(1):37-43

24. Zaidi A, Knight DS, Augustine DX et al. Echocardiographic Assessment of the Right Heart in Adults: A Practical Guideline from the British Society of Echocardiography. Echo Res Pract 2020;7(1):G19-G41

25. Vonk Noordegraaf A, Westerhof BE, Westerhof N. The Relationship Between the Right Ventricle and its Load in Pulmonary Hypertension. J Am Coll Cardiol 2017;69(2):236-243. doi:10.1016/j.jacc.2016.10.047

26. Todaro MC, Carerj S, Zito C et al. Echocardiographic Evaluation of Right Ventricular-Arterial Coupling in Pulmonary Hypertension. Am J Cardiovasc Dis 2020;10(4):272-283

27. Tello K, Axmann J, Ghofrani HA et al. Relevance of the TAPSE/PASP Ratio in Pulmonary Arterial Hypertension. Int J Cardiol2018;266:229-235

28. Ghio S, Guazzi M, Scardovi AB et al., on behalf of all investigators. Different Correlates but Similar Prognostic Implications for Right Ventricular Dysfunction in Heart Failure Patients With Reduced or Preserved Ejection Fraction. Eur J Heart Fail2017;19(7):873-879

29. Nakagawa A, Yasumura Y, Yoshida C et al., on behalf of Osaka CardioVascular Conference (OCVC) - Heart Failure Investigators. Prognostic Importance of Right Ventricular-Vascular Uncoupling in Acute Decompensated Heart Failure With Preserved Ejection Fraction.Circ Cardiovasc Imaging 2020;13:e011430. DOI:10.1161/CIRCIMAGING.120.011430

30. Fortuni F, Butcher SC, Dietz MF et al. Right Ventricular-Pulmonary Arterial Coupling in Secondary Tricuspid Regurgitation. Am $J$ Cardiol 2021;S0002-9149(21)00212-5. 
doi:10.1016/j.amjcard.2021.02.037

31. Tello K, Dalmer A, Axmann J et al. Reserve of Right Ventricular-Arterial Coupling in the Setting of Cronic Overload.Circ Heart Fail 2019;12:e005512. DOI:10.1161/CIRCHEARTFAILURE.118.005512

32. Tabima DM, Philip JL, Chesler NC. Right Ventricular-Pulmonary Vascular Interactions. Physiology (Bethesda) 2017;32(5):346-356

33. Brewis MJ, Bellofiore A, Vanderpool RR et al. Imaging Right Ventricular Function to Predict Outcome in Pulmonary Arterial Hypertension. Int J Cardiol 2016;218:206-211. doi: 10.1016/j.ijcard.2016.05.015

34. Vanderpool R, Rischard F, Naeije R et al. Simple Functional Imaging of the Right Ventricle in Pulmonary Hypertension: Can Right Ventricular Ejection Fraction be Improved? Int J Cardiol 2016;223:93-94. doi:10.1016/ijcard.2016.08.138

35. Naeije R, Brimioulle S, Dewachter L. Biomechanics of the Right Ventricle in Health and Disease (2013 Grover Conference Series).Pulm Circ 2014;4:395-406

36. Caraballo C, Desai NR, Mulder H et al. Clinical Implications of the New York Heart Association Classification $J$ Am Heart Assoc2019;8:e14240. DOI:10.1161/JAHA.119.014240

37. Pocock SJ, Wang D, Pfeffer MA et al., on Behalf of the CHARM Investigators. Predictors of Mortality and Morbidity in Patients with Chronic Heart Failure. Eur Heart $J$ 2006;27:65-75

38. Briongos-Figuero S, Estevez A, Perez ML et al. Prognostic Role of NYHA Class in Heart Failure Patients Undergoing Primary Prevention ICD Therapy. ESC Heart Fail 2020;7:280-284. DOI:10.1002/ehf2.12548

Table 1. Baseline clinical characteristics

\begin{tabular}{|c|c|c|c|c|c|}
\hline Variables & $\begin{array}{l}\text { All patients } \\
(\mathrm{n}=105)\end{array}$ & $\begin{array}{l}\text { NYHA I } \\
(n=11)\end{array}$ & $\begin{array}{l}\text { NYHA II } \\
(\mathrm{n}=54)\end{array}$ & $\begin{array}{l}\text { NYHA III-IV } \\
(\mathrm{n}=40)\end{array}$ & P-value \\
\hline Age (years) & $61 \pm 14$ & $51 \pm 10 \S++$ & $62 \pm 13$ & $62 \pm 14$ & 0.048 \\
\hline Men, $\mathrm{n}(\%)$ & $77(73 \%)$ & $9(82 \%)$ & $40(74 \%)$ & $28(70 \%)$ & 0.72 \\
\hline $\begin{array}{l}\text { Comorbidities, } \\
\mathrm{n}(\%)\end{array}$ & $\begin{array}{l}\text { Comorbidities, } \\
\mathrm{n}(\%)\end{array}$ & $\begin{array}{l}\text { Comorbidities, } \\
\mathrm{n}(\%)\end{array}$ & $\begin{array}{l}\text { Comorbidities, } \\
\mathrm{n}(\%)\end{array}$ & $\begin{array}{l}\text { Comorbidities, } \\
\mathrm{n}(\%)\end{array}$ & $\begin{array}{l}\text { Comorbidities, } \\
\mathrm{n}(\%)\end{array}$ \\
\hline Hypertension & $58(55 \%)$ & $4(36 \%)$ & $33(61 \%)$ & $21(53 \%)$ & 0.29 \\
\hline $\begin{array}{l}\text { Diabetes } \\
\text { mellitus }\end{array}$ & $19(18 \%)$ & $1(9 \%)$ & $9(17 \%)$ & $9(23 \%)$ & 0.55 \\
\hline Smoking, n(\%) & $43(41 \%)$ & $5(45 \%)$ & $24(44 \%)$ & $14(35 \%)$ & 0.62 \\
\hline $\begin{array}{l}\text { Medication, } \\
\mathrm{n}(\%)\end{array}$ & $\begin{array}{l}\text { Medication, } \\
\mathrm{n}(\%)\end{array}$ & $\begin{array}{l}\text { Medication, } \\
\mathrm{n}(\%)\end{array}$ & $\begin{array}{l}\text { Medication, } \\
\mathrm{n}(\%)\end{array}$ & $\begin{array}{l}\text { Medication, } \\
\mathrm{n}(\%)\end{array}$ & $\begin{array}{l}\text { Medication, } \\
\mathrm{n}(\%)\end{array}$ \\
\hline ACE-I/ARBs & $97(92 \%)$ & $9(82 \%)$ & $52(96 \%)$ & $36(90 \%)$ & 0.20 \\
\hline Beta-blocker & $100(95 \%)$ & $11(100 \%)$ & $52(96 \%)$ & $37(93 \%)$ & 0.67 \\
\hline MRA & $93(89 \%)$ & $7(64 \%) \S$ & $49(91 \%)$ & $37(93 \%)$ & 0.02 \\
\hline Loop diuretic & $72(69 \%)$ & $3(27 \%) \S++$ & $36(67 \%)$ & $33(83 \%)$ & 0.002 \\
\hline $\mathrm{BNP}(\mathrm{pg} / \mathrm{ml})$ & $280(101-665)$ & $\begin{array}{l}156(103-269) \\
\S\end{array}$ & $110(83-451) \S$ & $620(205-1250)$ & $<0.001$ \\
\hline
\end{tabular}




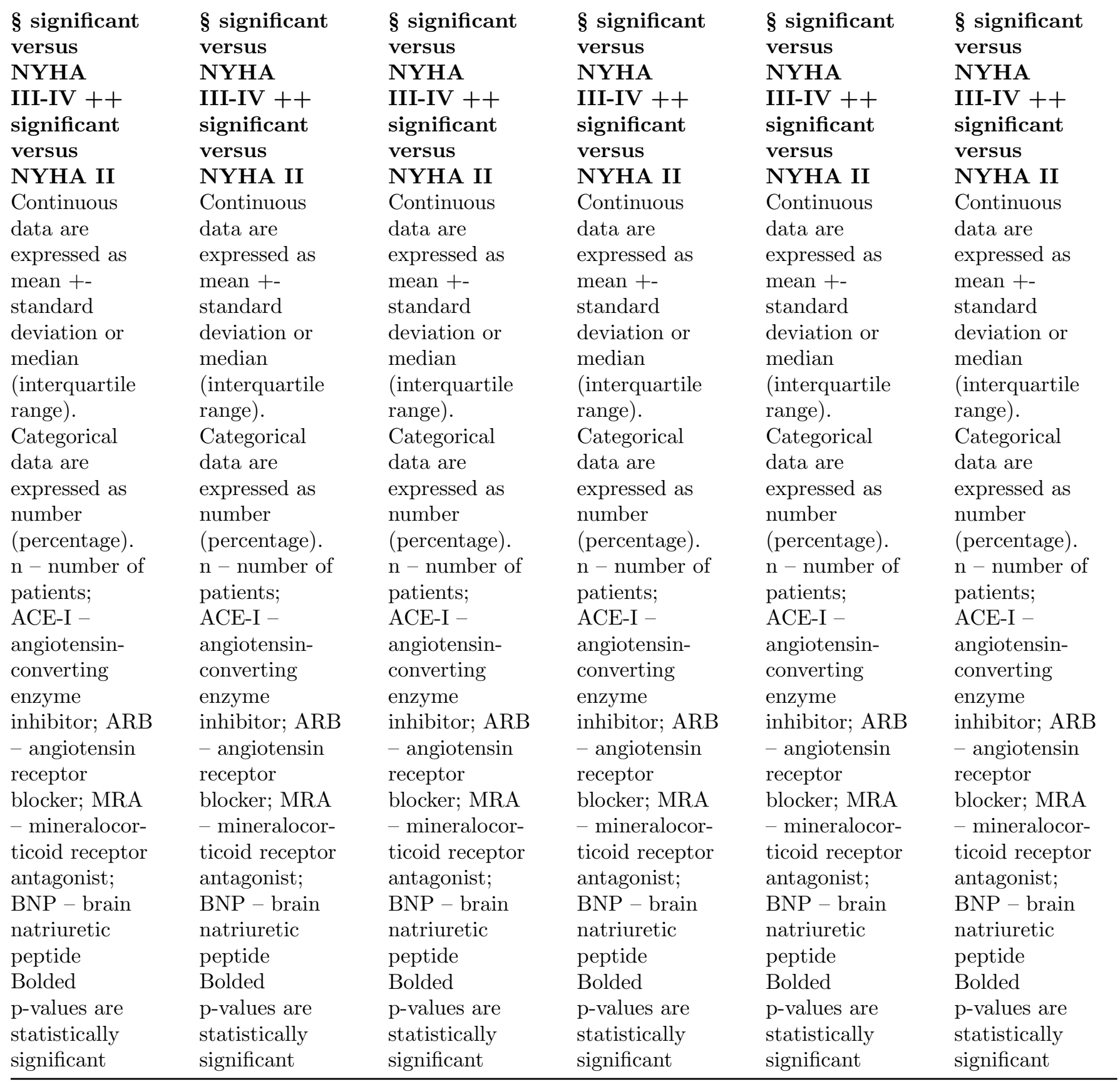

Table 2. Two-dimensional echocardiographic data

\begin{tabular}{|c|c|c|c|c|c|}
\hline Variables & $\begin{array}{l}\text { All patients } \\
(\mathrm{n}=105)\end{array}$ & $\begin{array}{l}\text { NYHA I } \\
(n=11)\end{array}$ & $\begin{array}{l}\text { NYHA II } \\
(\mathrm{n}=54)\end{array}$ & $\begin{array}{l}\text { NYHA III-IV } \\
(n=40)\end{array}$ & $\mathbf{P}$-value \\
\hline LV & LV & LV & LV & LV & LV \\
\hline $\begin{array}{l}\text { functional } \\
\text { parameters }\end{array}$ & $\begin{array}{l}\text { functional } \\
\text { parameters }\end{array}$ & $\begin{array}{l}\text { functional } \\
\text { parameters }\end{array}$ & $\begin{array}{l}\text { functional } \\
\text { parameters }\end{array}$ & $\begin{array}{l}\text { functional } \\
\text { parameters }\end{array}$ & $\begin{array}{l}\text { functional } \\
\text { parameters }\end{array}$ \\
\hline $\begin{array}{l}\text { LVEDV index } \\
\left(\mathrm{ml} / \mathrm{m}^{2}\right)\end{array}$ & $126 \pm 39$ & $144 \pm 49$ & $125 \pm 37$ & $123 \pm 38$ & 0.27 \\
\hline
\end{tabular}




\begin{tabular}{|c|c|c|c|c|c|}
\hline $\begin{array}{l}\text { LVESV index } \\
\left(\mathrm{ml} / \mathrm{m}^{2}\right)\end{array}$ & $92 \pm 32$ & $102 \pm 42$ & $89 \pm 29$ & $93 \pm 34$ & 0.51 \\
\hline LVEF (\%) & $28 \pm 7$ & $30 \pm 8$ & $29 \pm 7$ & $26 \pm 8$ & 0.06 \\
\hline $\begin{array}{l}\text { Mitral flow } \\
\text { parameters }\end{array}$ & $\begin{array}{l}\text { Mitral flow } \\
\text { parameters }\end{array}$ & $\begin{array}{l}\text { Mitral flow } \\
\text { parameters }\end{array}$ & $\begin{array}{l}\text { Mitral flow } \\
\text { parameters }\end{array}$ & $\begin{array}{l}\text { Mitral flow } \\
\text { parameters }\end{array}$ & $\begin{array}{l}\text { Mitral flow } \\
\text { parameters }\end{array}$ \\
\hline $\begin{array}{l}\text { E wave } \\
\text { velocity } \\
(\mathrm{cm} / \mathrm{s})\end{array}$ & $77 \pm 21$ & $71 \pm 15$ & $76 \pm 22$ & $80 \pm 23$ & 0.45 \\
\hline $\begin{array}{l}\text { E wave DT } \\
(\mathrm{ms})\end{array}$ & $174 \pm 45$ & $174 \pm 41$ & $178 \pm 49$ & $168 \pm 42$ & 0.59 \\
\hline $\begin{array}{l}\text { A wave } \\
\text { velocity } \\
(\mathrm{cm} / \mathrm{s})\end{array}$ & $69 \pm 22$ & $60 \pm 19$ & $73 \pm 22$ & $66 \pm 22$ & 0.08 \\
\hline $\mathrm{E} / \mathrm{A}$ ratio & $1.27 \pm 0.66$ & $0.90 \pm 0.25 \S$ & $1.16 \pm 0.57$ & $1.42 \pm 0.80$ & 0.04 \\
\hline $\begin{array}{l}\text { Average E/E' } \\
\text { ratio }\end{array}$ & $13.4 \pm 5.6$ & $11.4 \pm 3.1 \S$ & $12.2 \pm 4.2 \S$ & $15.5 \pm 7$ & 0.007 \\
\hline GLS-LV (\%) & $-7.9 \pm 2.9$ & $-9.8 \pm 3.2 \S$ & $-8.3 \pm 2.6 \S$ & $-6.7 \pm 2.8$ & 0.002 \\
\hline $\begin{array}{l}\text { LA volume } \\
\text { index }\left(\mathrm{ml} / \mathrm{m}^{2}\right)\end{array}$ & $48 \pm 22$ & $46 \pm 24$ & $47 \pm 22$ & $51 \pm 23$ & 0.66 \\
\hline RV & RV & RV & RV & RV & $\mathrm{RV}$ \\
\hline $\begin{array}{l}\text { functional } \\
\text { parameters }\end{array}$ & $\begin{array}{l}\text { functional } \\
\text { parameters }\end{array}$ & $\begin{array}{l}\text { functional } \\
\text { parameters }\end{array}$ & $\begin{array}{l}\text { functional } \\
\text { parameters }\end{array}$ & $\begin{array}{l}\text { functional } \\
\text { parameters }\end{array}$ & $\begin{array}{l}\text { functional } \\
\text { parameters }\end{array}$ \\
\hline $\begin{array}{l}\text { RV basal } \\
\text { diameter }(\mathrm{mm})\end{array}$ & $37 \pm 6$ & $36 \pm 6$ & $37 \pm 5$ & $38 \pm 7$ & 0.26 \\
\hline TAPSE (mm) & $18 \pm 4$ & $19 \pm 3 \S$ & $19 \pm 3 \S$ & $16 \pm 4$ & 0.002 \\
\hline $\begin{array}{l}\text { S wave } \\
\text { velocity } \\
(\mathrm{cm} / \mathrm{s})\end{array}$ & $10.6 \pm 2$ & $11.2 \pm 1.5$ & $11.2 \pm 1.7 \S$ & $9.7 \pm 2.3$ & 0.002 \\
\hline RV-FAC (\%) & $34 \pm 10$ & $34 \pm 7$ & $36 \pm 8$ & $32 \pm 11$ & 0.06 \\
\hline $\begin{array}{l}\text { Tricuspid flow } \\
\text { parameters }\end{array}$ & $\begin{array}{l}\text { Tricuspid flow } \\
\text { parameters }\end{array}$ & $\begin{array}{l}\text { Tricuspid flow } \\
\text { parameters }\end{array}$ & $\begin{array}{l}\text { Tricuspid flow } \\
\text { parameters }\end{array}$ & $\begin{array}{l}\text { Tricuspid flow } \\
\text { parameters }\end{array}$ & $\begin{array}{l}\text { Tricuspid flow } \\
\text { parameters }\end{array}$ \\
\hline $\begin{array}{l}\text { E wave } \\
\text { velocity } \\
(\mathrm{cm} / \mathrm{s})\end{array}$ & $54 \pm 11$ & $51 \pm 8$ & $54 \pm 10$ & $55 \pm 13$ & 0.50 \\
\hline $\begin{array}{l}\text { E wave DT } \\
(\mathrm{ms})\end{array}$ & $176 \pm 38$ & $184 \pm 22$ & $176 \pm 37$ & $175 \pm 43$ & 0.76 \\
\hline $\begin{array}{l}\text { A wave } \\
\text { velocity } \\
(\mathrm{cm} / \mathrm{s})\end{array}$ & $48 \pm 12$ & $55 \pm 10 \S$ & $48 \pm 11$ & $44 \pm 12$ & 0.01 \\
\hline $\mathrm{E} / \mathrm{A}$ ratio & $1.20 \pm 0.34$ & $0.96 \pm 0.28 \S$ & $1.18 \pm 0.34$ & $1.30 \pm 0.31$ & 0.01 \\
\hline GLS-RV (\%) & $-12 \pm 5$ & $-14.3 \pm 4.4$ & $-12.8 \pm 5 \S$ & $-10.3 \pm 4.6$ & 0.01 \\
\hline RVFW-LS (\%) & $-15 \pm 7.9$ & $-19.3 \pm 6.3 \S$ & $-15.8 \pm 7.6$ & $-12.8 \pm 8.2$ & 0.03 \\
\hline $\begin{array}{l}\text { RA volume } \\
\text { index }(\mathrm{ml} / \mathrm{m} 2)\end{array}$ & $24(19-35)$ & $23(16-35)$ & $26(20-35)$ & $24(18-35)$ & 0.98 \\
\hline $\begin{array}{l}\text { More than } \\
\text { mild TR, } \mathrm{n}(\%)\end{array}$ & $20(19 \%)$ & $2(18 \%)$ & $6(11 \%)$ & $12(30 \%)$ & 0.07 \\
\hline $\begin{array}{l}\text { PASP ( } \\
\text { Hg) }\end{array}$ & $30(22-39)$ & $30(26-34)$ & $28(22-34)$ & $32(21-44)$ & 0.29 \\
\hline
\end{tabular}




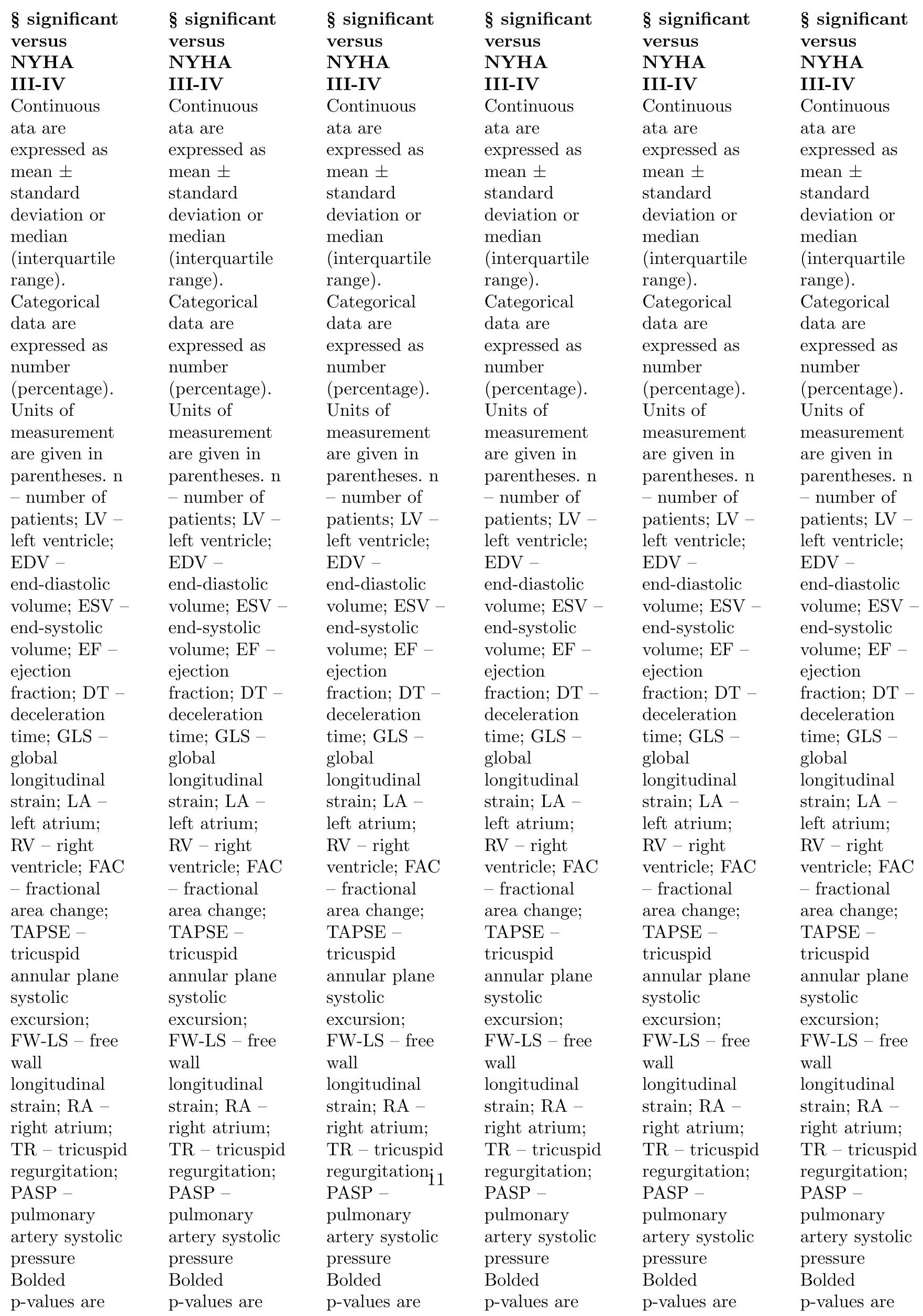


Table 3. Three-dimensional echocardiographic data

\begin{tabular}{|c|c|c|c|c|c|}
\hline Variables & $\begin{array}{l}\text { All patients } \\
(\mathrm{n}=105)\end{array}$ & $\begin{array}{l}\text { NYHA I } \\
(n=11)\end{array}$ & $\begin{array}{l}\text { NYHA II } \\
(\mathrm{n}=54)\end{array}$ & $\begin{array}{l}\text { NYHA III-IV } \\
(\mathrm{n}=40)\end{array}$ & P-value \\
\hline LV & LV & LV & LV & LV & LV \\
\hline functional & functional & functional & functional & functional & functional \\
\hline parameters & parameters & parameters & parameters & parameters & parameters \\
\hline LVEF (\%) & $28 \pm 7$ & $30 \pm 8$ & $29 \pm 6$ & $27 \pm 7$ & 0.34 \\
\hline RV & RV & RV & RV & $\mathbf{R V}$ & RV \\
\hline functional & functional & functional & functional & functional & functional \\
\hline parameters & parameters & parameters & parameters & parameters & parameters \\
\hline $\operatorname{RVEDV}(\mathrm{ml})$ & $162 \pm 61$ & $168 \pm 54$ & $165 \pm 61$ & $157 \pm 62$ & 0.77 \\
\hline $\operatorname{RVESV}(\mathrm{ml})$ & $95 \pm 41$ & $94 \pm 36$ & $92 \pm 41$ & $99 \pm 44$ & 0.77 \\
\hline $\begin{array}{l}\text { RV stroke } \\
\text { volume }(\mathrm{ml})\end{array}$ & $63(50-75)$ & $66(59-75)$ & $67(51-84) \S$ & $58(38-70)$ & 0.02 \\
\hline $\operatorname{RVEF}(\%)$ & $42 \pm 9$ & $45 \pm 6 \S$ & $45 \pm 9 \S$ & $38 \pm 8$ & 0.001 \\
\hline RVPAC & $0.77 \pm 0.30$ & $0.83 \pm 0.18 \S$ & $0.86 \pm 0.34 \S$ & $0.64 \pm 0.21$ & 0.001 \\
\hline
\end{tabular}




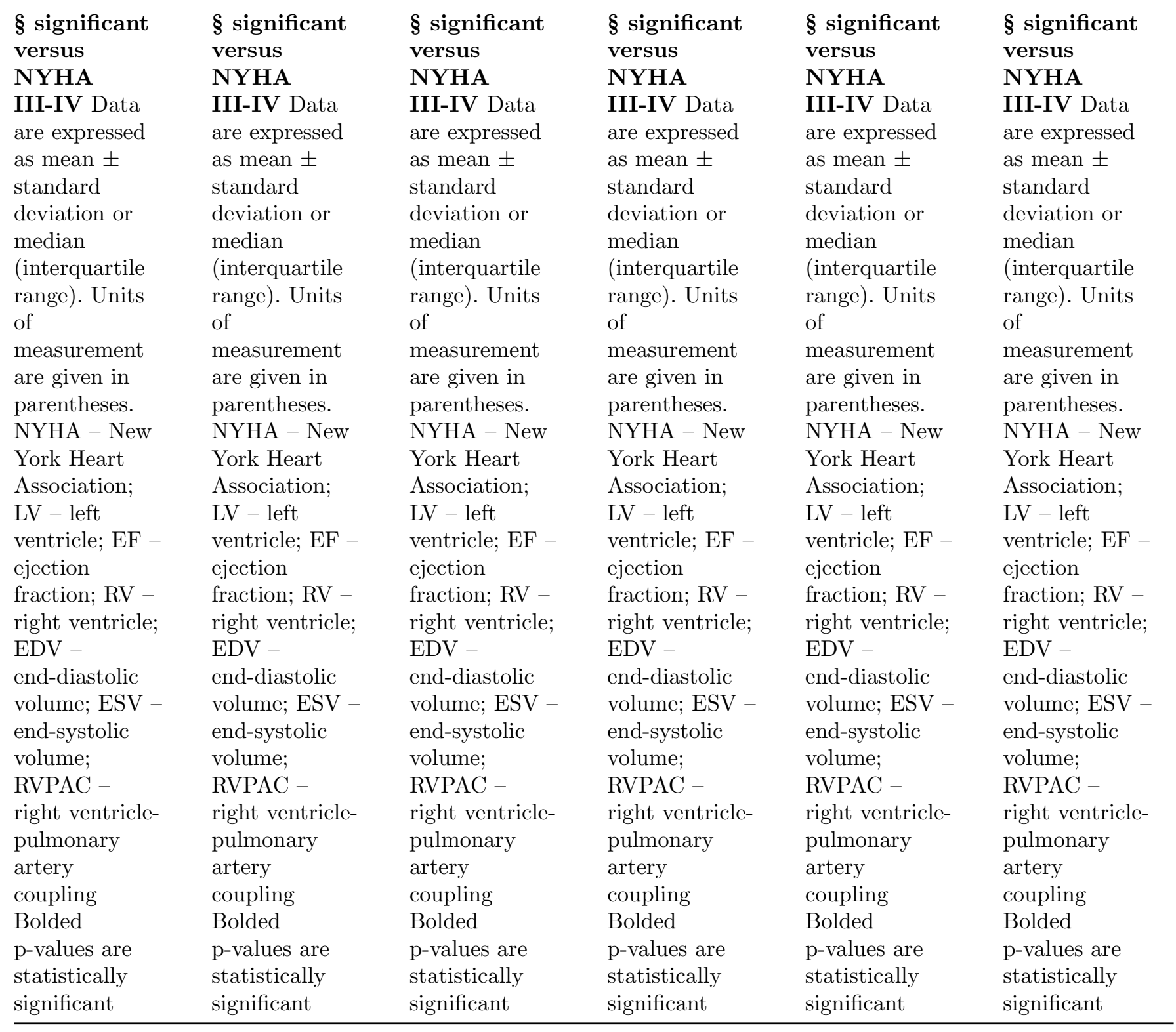

Table 4. Univariable binary logistic regression analysis

Variables

Clinical characteristics

Age (years)

Diuretic use

Parameters of LV systolic function

2D LVEF

GLS-LV

Parameters of LV diastolic function

Mitral E/E' ratio

LA volume index

Parameters of RV function 
S wave velocity

TAPSE

GLS-RV

RVFW-LS

RVPAC

PASP

OR - odds ratio; CI - confidence interval; LV - left ventricle; 2D - two dimensional; EF - ejection fraction; GLS - global lo

Table 5. AUC and optimal cut-off values for parameters to identify patients with severe HF symptoms

\section{Parameter}

LVEF

GLS-LV

S wave velocity

TAPSE

GLS-RV

RVPAC

PASP

AUC - area under the curve; HF - heart failure; CI - confidence interval; LV - left ventricle; EF - ejection fraction; GLS-

Table 6. Multivariable binary logistic regression analysis

\section{Variables}

Age

Diuretic use

GLS-LV

E/E' ratio

RVPAC

PASP

OR - odds ratio; CI - confidence interval; GLS-LV - global longitudinal strain of the left ventricle; RVPAC - right ventricle

\section{Figure legends}

Figure 1. Three-dimensional volumetric assessment of the RV using dedicated software. RV - right ventricle; ESV - end-systolic volume; EDV - end-diastolic volume; EF - ejection fraction; SV - stroke volume

Figure 2. Boxplots showing lower values of RVPAC with increasing NYHA class. RVPAC - right ventriclepulmonary artery coupling; NYHA - New York Heart Association 


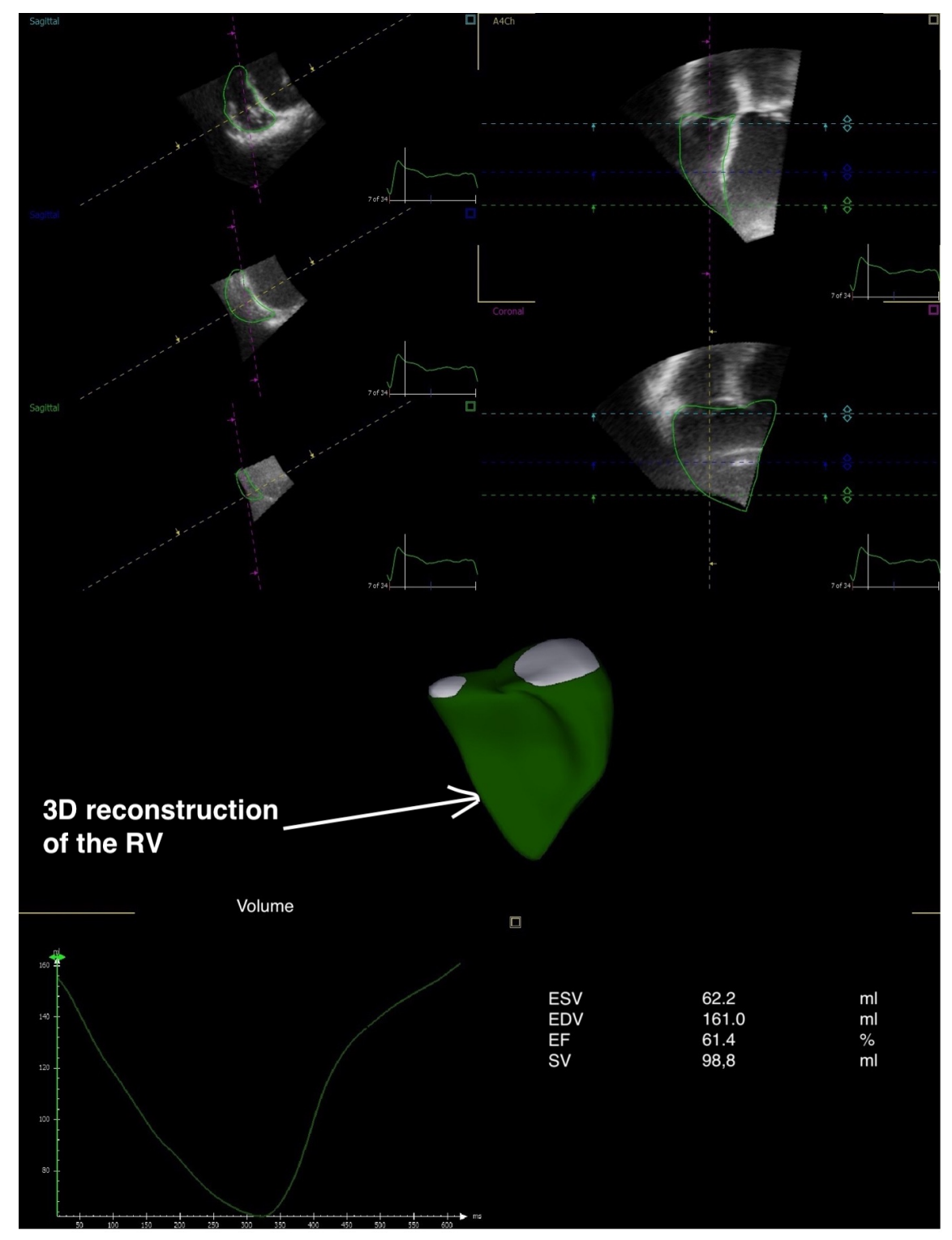




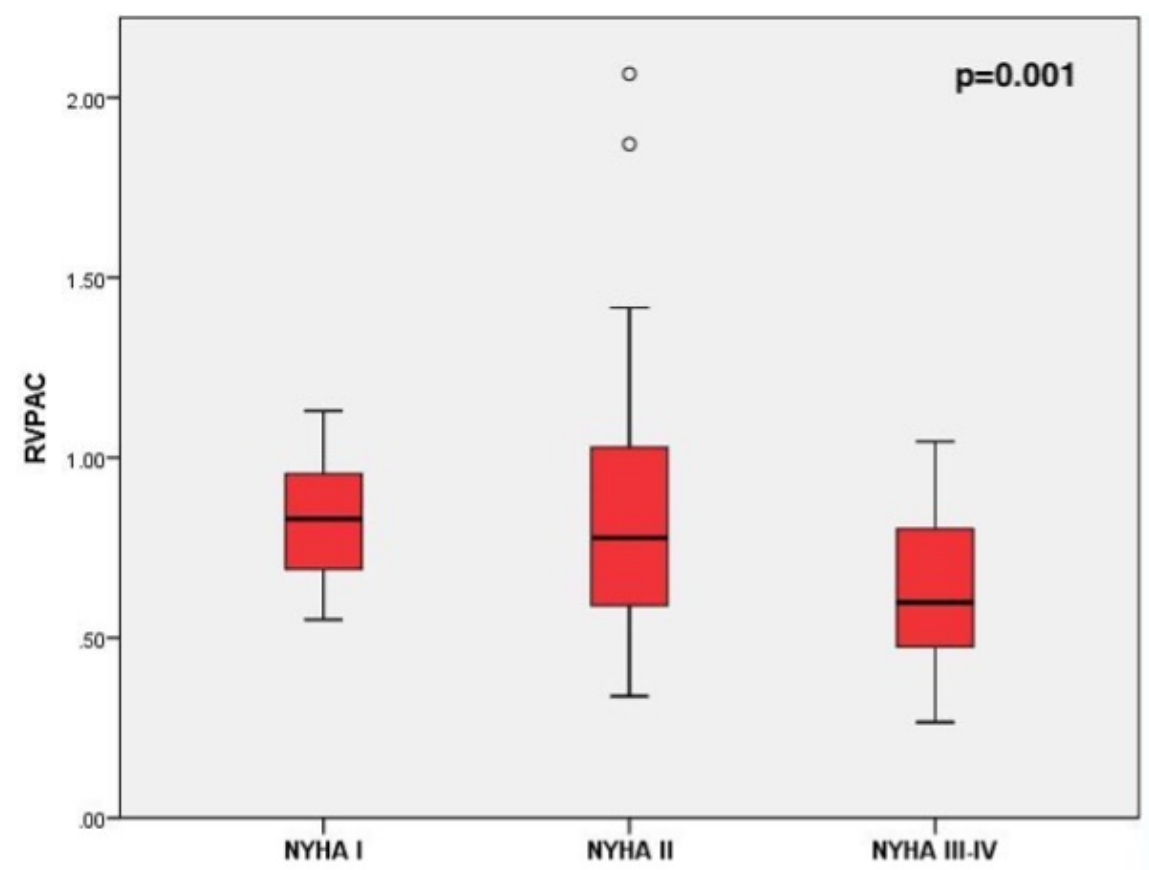

